\title{
Comment on "Can the neutrophil/lymphocyte ratio (NLR) have a role in the diagnosis of coronavirus 2019 disease (COVID-19)?"
}

\author{
Cihan Bedel ${ }^{*} \oplus$, Mustafa Korkut $\odot$, Hamit Hakan Armağan²
}

We read with great interest the article "Can the neutrophil/lymphocyte ratio (NLR) have a role in the diagnosis of coronavirus 2019 disease (COVID-19)?” by Nalbant et al ${ }^{1}$. They aimed to evaluate the role of neutrophil/lymphocyte ratio (NLR), an inflammation marker in the diagnosis of COVID-19. They concluded that NLR is an independent predictor for the diagnosis of COVID-19. First of all, We congratulate the authors for their invaluable contribution to the literatüre. However, we think that some points should be discussed about the study.

White blood cell count, CRP, and immature granulocyte are useful inflammatory biomarkers in clinical practice ${ }^{2,3}$. An easily measurable laboratory marker is used to evaluate systemic inflammation, particularly the WBC subtypes NLR and platelet/lymphocyte ratio (PLR) ${ }^{4}$. However, these parameters are affected by many factors such as acute coronary syndromes, local or systemic infection, previous history of infection, inflammatory diseases, renal or hepatic dysfunction and known malignancy ${ }^{2-5}$. For these reasons, it would be better if the authors had mentioned these factors.

It is well known that some drug use, such as corticosteroids, can increase neutrophils and decrease lymphocytes.
For this reason, more accurate results can be obtained by excluding or identifying patients with drug use that may cause an increase in NLR in patients in the groups. In addition, plasma inflammatory biomarkers and NLR are time sensitive variables. It is known that ischemic events can increase $\mathrm{NLR}^{6}$. Therefore, it is important to define the time from the first symptom to sample collection. As a result, NLR can be affected by many factors. We think that there are still gaps in the clinic regarding the routine use of these parameters in critically ill patients. Larger prospective studies are needed to demonstrate the importance of NLR in COVID-19 on this topic.

\section{AUTHORS'CONTRIBUTION}

CB: Conceptualization, Data Curation, Formal Analysis, Writing - Original Draft, Writing - Review \& Editing. MK: Conceptualization, Data Curation, Formal Analysis, Writing - Original Draft, Writing - Review \& Editing. HHA: Conceptualization, Data Curation, Formal Analysis, Writing - Original Draft, Writing - Review \& Editing.

\footnotetext{
'Unıversıty of Health Sciences, Antalya Training and Research Hospital Physician, Department of Emergency Medicine - Antalya, Turkey.

${ }^{2}$ Suleyman Demirel University, Faculty of Medicine, Department of Emergency Medicine - Isparta, Turkey.

*Corresponding author: cihanbedel@hotmail.com

Conflicts of interest: the authors declare there are no conflicts of interest. Funding: none.

Received on September 21, 2020. Accepted on October 21, 2020.
} 


\section{REFERENCES}

1. Nalbant A, Kaya T, Varim C, Yaylaci S, Tamer A, Cinemre H. Can the neutrophil/lymphocyte ratio (NLR) have a role in the diagnosis of coronavirus 2019 disease (COVID-19)? Rev Assoc Med Bras. 2020;66(6):746-51. https://doi.org/10.1590/18069282.66.6.746

2. Hu H, Yao X, Xie X, Wu X, Zheng C, Xia W, et al. Prognostic value of preoperative NLR, dNLR, PLR and CRP in surgical renal cell carcinoma patients. World J Urol. 2017;35(2):261-70. https://doi.org/10.1007/s00345-016-1864-9

3. Bedel C, Korkut M, Aksoy F, Kus G. Usefulness of ımmature granulocytes to predict high coronary SYNTAX score in acute coronary syndrome: a cross-sectional study. Arch Acad Emerg Med. 2020;8(1):e73. PMID: 33134969
4. Ince N, Güçlü E, Sungur MA, Karabay O. Evaluation of neutrophil to lymphocyte ratio, platelet to lymphocyte ratio, and lymphocyte to monocyte ratio in patients with cellulitis. Rev Assoc Med Bras (1992). 2020;66(8):1077-81. https://doi. org/10.1590/1806-9282.66.8.1077

5. Bedel C, Selvi F. Association of platelet to lymphocyte and neutrophil to lymphocyte ratios with in-hospital mortality in patients with type A acute aortic dissection. Braz J Cardiovasc Surg. 2019;34(6):694-8. https://doi.org/10.21470/1678-9741-2018-0343

6. Gary T, Pichler M, Belaj K, Hafner F, Gerger A, Froehlich H, et al. Neutrophil to- lymphocyte ratio and its association with critical limb ischemia in PAOD patients. PLoS One. 2013;8(2):e56745. https://doi.org/10.1371/journal.pone.0056745 